\title{
Prognostic Significance and Clinicopathological Features of Synchronous Colorectal Cancer
}

\author{
KEIICHI ARAKAWA, KEISUKE HATA, HIROAKI NOZAWA, KAZUSHIGE KAWAI, TOSHIAKI TANAKA, \\ TAKESHI NISHIKAWA, KAZUHITO SASAKI, YASUTAKA SHUNO, MANABU KANEKO, MASAYA HIYOSHI, \\ SHIGENOBU EMOTO, KOJI MURONO, HIROFUMI SONODA and SOICHIRO ISHIHARA
}

Department of Surgical Oncology, the University of Tokyo Hospital, Tokyo, Japan

\begin{abstract}
Aim: This study aimed to clarify the difference in the clinicopathological and prognostic features between synchronous colorectal cancer (CRC) and solitary CRC. Materials and Methods: A retrospective analysis was conducted in patients with synchronous and solitary CRC. Results: A total of 92 (7.1\%) out of 1,295 consecutive patients had synchronous CRC. Mucinous adenocarcinoma was more frequent in patients with synchronous CRC than in those with solitary CRC (13.0\% vs. 3.7\%; $p<0.001)$. The 5-year relapse-free survival (RFS) rate was poorer in patients with synchronous $C R C$ than in those with solitary CRC (65.3\% vs. $75.1 \%$; $p=0.035)$, which was contrived by the multivariate analysis (hazard ratio=1.52(HR); $p=0.039)$. Conclusion: Patients with synchronous CRC had a poorer RFS than those with solitary CRC; thus, patients with synchronous $C R C$ might require more intensive care than those with solitary CRC in follow-up.
\end{abstract}

The incidence of synchronous colorectal cancer (CRC) is reported to be between $1.1 \%$ and $8.1 \%$ (1-3). Synchronous $\mathrm{CRC}$ is characterized by the presence of separate tumors derived from the same genetic and environmental background. However, no consensus exists as to its clinicopathological characteristics. Previously reported risk factors for synchronous CRC include age, male sex, and adenomatous polyposis $(1,4)$. With respect to prognosis, several studies have reported that survival was better in patients with synchronous CRC than in those with solitary CRC (4-7), while other studies showed that there was no

Correspondence to: Keiichi Arakawa, Department of Surgical Oncology, the University of Tokyo Hospital, 7-3-1 Hongo, Bunkyoku, Tokyo 113-8655, Japan. Tel: +81 338155411 ext. 37083, Fax: +81338116822, e-mail: keiichiarakawa@hotmail.com

Key Words: Colorectal cancer, relapse-free survival, solitary, synchronous. significant difference $(1,3)$. Therefore, whether synchronous CRC is associated with a poorer outcome than solitary CRC remains controversial $(1,8)$. This controversy may be due to the small number of patients with synchronous CRC. The majority of studies included 50 patients or fewer. A recent large-scale study reported that synchronous CRC was detected in $3.8 \%$ of patients, although clinicopathological characteristics were not analyzed (3).

This study aimed to determine the clinicopathological and prognostic features of synchronous CRC in a large group of Japanese patients.

\section{Materials and Methods}

Patients. A retrospective analysis was conducted in 1,295 consecutive patients who underwent surgical resection for CRC at the Department of Surgical Oncology at the University of Tokyo Hospital (Tokyo, Japan) between 2005 and 2015. Data were collected from treatment records. Participants were stratified into synchronous and solitary CRC groups. Clinicopathological characteristics, overall survival (OS), and relapse-free survival (RFS) were analyzed. Patients with inflammatory bowel disease or familial adenomatous polyposis were excluded. Synchronous CRC was defined according to the three-part definition of Warren and Gates (9), which has been used in previous studies: (i) the tumors must be malignant, (ii) the tumors must be separated from one another and must not have metastasized, and (iii) the tumors must have been diagnosed together or at most 6 months apart. Two types of clinicopathological analyses were performed, namely between patients and between tumors. The extent of tumor progression was assessed according to the Union for International Cancer Control tumor-node-metastasis classification (10). In synchronous CRC, the index lesion was defined as the deepest tumor, and the clinicopathological characteristics of the index lesion were used in the analysis of each patient (8).

The study was approved by the Ethical Review Board of Tokyo University (Tokyo, Japan) (approval number: 3252-[6]). Research was conducted in accordance with the Declaration of Helsinki and Title 45 of the United States Code of Federal Regulations, Part 46, Protection of Human Subjects, effective December 13, 2001. 
Table I. Clinicopathological characteristics of synchronous and solitary colorectal cancer cases.

\begin{tabular}{|c|c|c|c|c|}
\hline Characteristic & Total $(\mathrm{n}=1,295)$ & Synchronous $(\mathrm{n}=92 ; 7.1 \%)$ & Solitary $(\mathrm{n}=1,203 ; 92.9 \%)$ & $p$-Value \\
\hline \multicolumn{5}{|l|}{ Age (years) } \\
\hline Median (range) & $67(26-93)$ & $69(37-90)$ & $67(26-93)$ & 0.155 \\
\hline \multicolumn{5}{|l|}{ Gender, n (\%) } \\
\hline Male & $753(58.1)$ & $54(58.7)$ & $699(58.1)$ & \multirow[t]{2}{*}{0.912} \\
\hline Female & $542(41.9)$ & $38(41.3)$ & $504(41.9)$ & \\
\hline \multicolumn{5}{|c|}{ CEA level (ng/ml), n (\%) } \\
\hline Median (range) & $4.7(0.6-6,841.0)$ & $5.3(1.0-1,406.0)$ & $4.6(0.6-6,841.0)$ & 0.076 \\
\hline$<5.0$ & $676(52.2)$ & $41(44.6)$ & $635(52.8)$ & \multirow{2}{*}{0.128} \\
\hline$\geq 5.0$ & $619(47.8)$ & $51(55.4)$ & $568(47.2)$ & \\
\hline \multicolumn{5}{|c|}{ CA19-9 level (ng/ml), n (\%) } \\
\hline Median (range) & $12(1-13,250)$ & $13(1-1,106)$ & $12(1-13,250)$ & 0.483 \\
\hline$<37$ & $1,036(80.0)$ & $69(75.0)$ & $967(80.4)$ & \multirow{2}{*}{0.226} \\
\hline$\geq 37$ & $289(20.0)$ & $23(25.0)$ & $236(19.6)$ & \\
\hline \multicolumn{5}{|c|}{ Tumor location, n (\%) } \\
\hline Right & $398(30.7)$ & $21(22.8)$ & $377(31.3)$ & \multirow[t]{2}{*}{0.080} \\
\hline Left & $897(69.3)$ & $71(77.2)$ & $826(68.7)$ & \\
\hline \multicolumn{5}{|c|}{ Tumor diameter $(\mathrm{mm}), \mathrm{n}(\%)$} \\
\hline Median (range) & $40(5-155)$ & $40(12-120)$ & $40(5-155)$ & 0.108 \\
\hline$<50$ & $847(65.4)$ & $51(55.4)$ & $796(66.2)$ & \multirow{2}{*}{0.040} \\
\hline$\geq 50$ & $448(34.6)$ & $41(44.6)$ & $407(33.8)$ & \\
\hline \multicolumn{5}{|l|}{ Pathology, n (\%) } \\
\hline Well/mod & $1203(92.9)$ & $73(79.4)$ & $1119(93.0)$ & $<0.001$ \\
\hline Poor/muc & $92(7.1)$ & $19(20.6)$ & $84(7.0)$ & - \\
\hline Poor & - & $7(7.6)$ & $39(3.2)$ & 0.0542 \\
\hline Muc & - & $12(13.0)$ & $45(3.7)$ & $<0.001$ \\
\hline \multicolumn{5}{|l|}{ T-Stage, n (\%) } \\
\hline 1 & $168(12.7)$ & $9(9.8)$ & $156(13.0)$ & \multirow[t]{4}{*}{0.022} \\
\hline 2 & $198(15.3)$ & $15(16.3)$ & $183(15.2)$ & \\
\hline 3 & $602(46.5)$ & $44(47.8)$ & $558(46.4)$ & \\
\hline 4 & $328(25.5)$ & $24(25.9)$ & $306(25.4)$ & \\
\hline \multicolumn{5}{|c|}{ T1-T2 vs. T3-T4, n (\%) } \\
\hline $1-2$ & $361(27.9)$ & $23(25.0)$ & $338(28.1)$ & \multirow[t]{2}{*}{0.519} \\
\hline $3-4$ & $934(72.1)$ & $69(75.0)$ & 865 (71.9) & \\
\hline \multicolumn{5}{|l|}{ LNM, n (\%) } \\
\hline Absent & $726(56.1)$ & $50(54.4)$ & $676(56.2)$ & \multirow[t]{2}{*}{0.731} \\
\hline Present & $569(43.9)$ & $42(45.6)$ & $527(43.8)$ & \\
\hline \multicolumn{5}{|c|}{ Lymphatic invasion, n (\%) } \\
\hline Absent & $874(67.5)$ & $62(67.4)$ & $812(67.5)$ & \multirow[t]{2}{*}{0.983} \\
\hline Present & $421(32.5)$ & $30(32.6)$ & $391(32.5)$ & \\
\hline \multicolumn{5}{|c|}{ Venous invasion, $\mathrm{n}(\%)$} \\
\hline Absent & $359(27.7)$ & $26(28.3)$ & $333(27.7)$ & 0.905 \\
\hline Invasion & $936(72.3)$ & $66(71.7)$ & $870(72.3)$ & \\
\hline Stage, n (\%) & & & & \\
\hline I & $271(21.0)$ & $13(14.1)$ & $258(21.5)$ & 0.328 \\
\hline II & $416(32.1)$ & $33(35.9)$ & $383(31.8)$ & \\
\hline III & $434(33.5)$ & $33(35.9)$ & $401(33.3)$ & \\
\hline IV & $174(13.4)$ & $13(13.4)$ & $161(13.4)$ & \\
\hline Stages I-II $v s$.III-I & & & & \\
\hline I-II & $687(53.1)$ & $47(51.1)$ & $640(53.2)$ & 0.690 \\
\hline III-IV & 607 (46.9) & 45 (48.9) & $562(46.8)$ & \\
\hline
\end{tabular}

CA19-9, Cancer antigen 19-9; CEA, carcinoembryonic antigen; LNM, lymph node metastasis; mod, moderately differentiated adenocarcinoma; muc, mucinous adenocarcinoma; poor, poorly differentiated adenocarcinoma; sig, signet-ring cell carcinoma; well, well-differentiated adenocarcinoma. Significant $p$-values are shown in bold.

Statistical analyses. Continuous variables were compared using the Student's $t$-test or Mann-Whitney $U$-test, and categorical variables were compared using the chi-square test or Fisher's exact test. Survival curves were plotted using the Kaplan-Meier method and compared using the log-rank test. Hazard ratios for
OS and RFS were calculated using univariate and multivariate Cox proportional hazards regression models. Statistical analyses were conducted using JMP Pro version 13.0.0 (SAS Institute Inc., Cary, NC, USA). A $p$-value of less than 0.05 was considered significant. 
Table II. Clinicopathological characteristics of synchronous and solitary colorectal cancer.

\begin{tabular}{lccl}
\hline Characteristic & $\begin{array}{c}\text { Synchronous } \\
(\mathrm{n}=200)\end{array}$ & $\begin{array}{c}\text { Solitary } \\
(\mathrm{n}=1,203)\end{array}$ & $p$-Value \\
& & & \\
\hline $\begin{array}{l}\text { Tumor location, n (\%) } \\
\quad \text { Right }\end{array}$ & $53(26.5)$ & $377(31.3)$ & 0.165 \\
$\quad$ Left & $147(73.5)$ & $826(68.7)$ & \\
$\begin{array}{l}\text { Pathology, n (\%) } \\
\quad \text { Well/mod }\end{array}$ & $175(87.5)$ & $1119(77.1)$ & - \\
$\quad$ Poor/muc & $25(12.5)$ & $84(6.9)$ & $\mathbf{0 . 0 1 1}$ \\
$\quad$ Poor & $12(6.0)$ & $39(3.2)$ & 0.072 \\
$\quad$ Muc & $13(6.5)$ & $45(3.7)$ & 0.088 \\
T-Stage, n (\%) & & & \\
$\quad$ 1 & $71(35.5)$ & $156(13.0)$ & - \\
2 & $33(16.5)$ & $183(15.2)$ & - \\
3 & $70(35.0)$ & $558(46.4)$ & - \\
$\quad 4$ & $26(13.0)$ & $306(25.4)$ & - \\
T1-T2 vs. T3-T4, n (\%) & & & \\
$1-2$ & $104(52.0)$ & $339(28.1)$ & $<\mathbf{0 . 0 0 1}$ \\
$3-4$ & $96(48.0)$ & $864(71.9)$ & \\
\hline
\end{tabular}

Mod, Moderately differentiated adenocarcinoma; muc, mucinous adenocarcinoma; poor, poorly differentiated adenocarcinoma; sig, signet-ring cell carcinoma; well, well-differentiated adenocarcinoma. Significant $p$-values are shown in bold.

\section{Results}

Clinicopathological characteristics. Of the 1,295 patients enrolled in this study, $92(7.1 \%)$ had synchronous CRC and $1,203(92.9 \%)$ had solitary CRC. A total of 79 patients had two tumors, 10 had three tumors, and three had four tumors The median follow-up period was 3.7 (range=0.1-12.0) years. The clinicopathological characteristics of the patients are summarized in Table I.

A greater proportion of patients with synchronous CRC had a larger lesion with a tumor diameter of $\geq 50 \mathrm{~mm}$ compared with those with solitary CRC (44.6\% vs. 33.8\%; $p=0.040)$. Histological findings revealed that mucinous adenocarcinoma (MAC) was more frequent in the synchronous CRC group than in the group with solitary CRC $(13.0 \%$ vs. $3.7 \%$; $p<0.001)$. No significant differences were observed in other variables, such as age, sex, and depth of invasion.

The clinicopathological characteristics of the tumors are summarized in Table II. Patients with synchronous CRC were observed to have a greater proportion of $\mathrm{T} 1-\mathrm{T} 2$ tumors than those with solitary CRC (52.0\% vs. 28.1\%; $p<0.001)$.

Survival analyses. The outcomes of the prognostic analysis are shown in Figure 1. No significant difference in 5-year OS was observed. However, patients with synchronous CRC had poorer 5-year RFS than did those with solitary CRC (65.3\% vs. $75.1 \% ; p=0.035)$.
Table III. Multivariate analysis of overall survival.

\begin{tabular}{|c|c|c|c|}
\hline \multirow[t]{2}{*}{ Factor } & \multirow{2}{*}{$\begin{array}{l}\text { Univariate } \\
\text { analysis } \\
p \text {-Value }\end{array}$} & \multicolumn{2}{|c|}{$\begin{array}{c}\text { Multivariate } \\
\text { analysis }\end{array}$} \\
\hline & & HR $(95.0 \% \mathrm{CI})$ & $p$-Value \\
\hline \multicolumn{4}{|l|}{ Age } \\
\hline$<50 v s . \geq 50$ years & 0.957 & - & - \\
\hline \multicolumn{4}{|l|}{ Gender } \\
\hline Male $v s$. female & 0.364 & - & - \\
\hline \multicolumn{4}{|l|}{ CEA } \\
\hline$<5.0 v s . \geq 5.0 \mathrm{ng} / \mathrm{ml}$ & $<0.001$ & $1.50(1.11-2.05)$ & 0.009 \\
\hline \multicolumn{4}{|l|}{ CA19-9 } \\
\hline$<37$ vs. $\geq 37 \mathrm{ng} / \mathrm{ml}$ & $<0.001$ & $1.43(1.06-1.90)$ & 0.017 \\
\hline \multicolumn{4}{|l|}{ Tumor location } \\
\hline Right $v s$. left & 0.678 & - & - \\
\hline \multicolumn{4}{|l|}{ Pathology } \\
\hline Well/mod $v s$. poor/muc & $<0.001$ & $1.41(1.07-1.84)$ & 0.012 \\
\hline \multicolumn{4}{|l|}{ T-Stage } \\
\hline 1-2 vs. 3-4 & $<0.001$ & $1.74(1.18-2.66)$ & 0.008 \\
\hline \multicolumn{4}{|l|}{ N-Stage } \\
\hline $0 v s .1$ & $<0.001$ & $1.22(0.91-1.64)$ & 0.193 \\
\hline \multicolumn{4}{|l|}{ M-Stage } \\
\hline 0 vs. 1 & $<0.001$ & $3.36(2.51-4.48)$ & $<0.001$ \\
\hline \multicolumn{4}{|l|}{ Lymphatic invasion } \\
\hline Absent $v s$. present & $<0.001$ & $1.35(1.01-1.79)$ & 0.040 \\
\hline \multicolumn{4}{|l|}{ Venous invasion } \\
\hline Absent vs. present & $<0.001$ & $1.48(1.01-2.22)$ & 0.051 \\
\hline \multicolumn{4}{|l|}{$\mathrm{CRC}$} \\
\hline Solitary vs. synchronous & 0.491 & - & - \\
\hline
\end{tabular}

CA19-9, Cancer antigen 19-9; CEA, carcinoembryonic antigen; CI, confidence interval; CRC, colorectal cancer; HR, hazard ratio; mod, moderately differentiated adenocarcinoma; muc, mucinous adenocarcinoma; poor, poorly differentiated adenocarcinoma; well, welldifferentiated adenocarcinoma. Significant p-values are shown in bold.

Kaplan-Meier curves for OS and RFS according to tumornode-metastasis stage are shown in Figures 2 and 3, respectively. No statistically significant difference in 5-year OS was observed between the two groups. However, patients with synchronous CRC tended to have a poorer RFS than those with solitary CRC in stage IV $(p=0.083)$.

The results of the univariate and multivariate analyses of OS and RFS are shown in Tables III and IV, respectively. Although no significant difference in OS was observed between the synchronous and solitary CRC groups, synchronous $\mathrm{CRC}$ was found to be an independent poor prognostic factor for RFS (hazard ratio $=1.52 ; p=0.039$ ).

\section{Discussion}

In the present study, we compared the clinicopathological features and prognostic outcomes of patients with synchronous and solitary CRC. Patients with synchronous CRC had significantly poorer 5-year RFS than those with solitary CRC. 
a

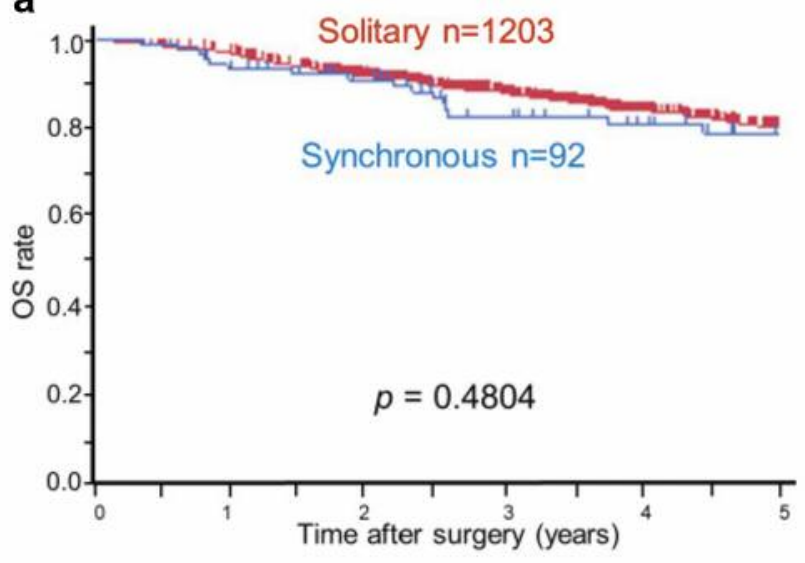

b

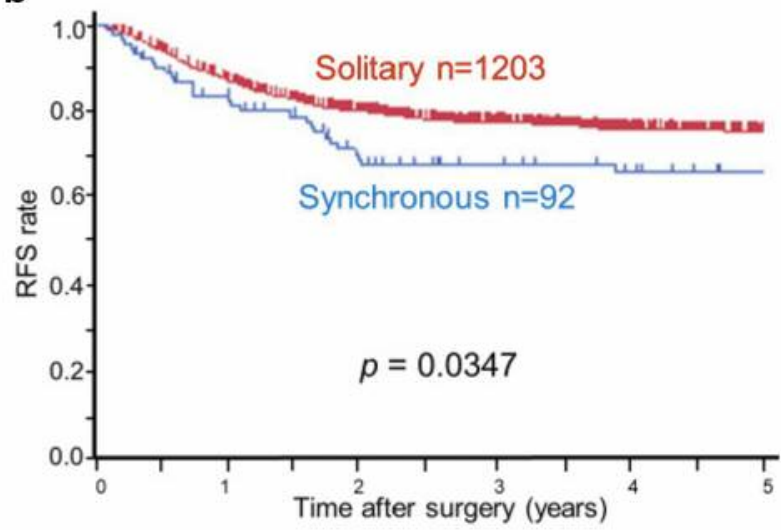

Figure 1. Kaplan-Meier curves of overall survival $(O S)($ a) and relapsefree survival $(R F S)(b)$. Blue lines represent patients with synchronous colorectal cancer (CRC); red lines represent patients with solitary CRC.

To our knowledge, this is the first report demonstrating a poorer RFS for patients with synchronous CRC.

Two previous studies have been conducted in patients with synchronous CRC $(1,8)$. However, whether synchronous CRC is associated with a poorer outcome than solitary CRC remained controversial. While several reports have demonstrated a poorer prognosis for synchronous CRC using univariate analysis, only two studies have demonstrated a poorer prognosis using multivariate analysis $(4,7)$. In the only prospective study analyzing the prognosis of synchronous CRC, Nosho et al. reported that OS was significantly poorer for patients with synchronous CRC (7). The authors speculated that this was due to the rate of metastasis of synchronous CRC. Oya et al. (6). also concluded the same. In the present study, synchronous CRC was associated with poorer RFS. One possible explanation is that, considering the possibility of each tumor recurrence, the relapse rate would be expected to be higher than that for solitary tumors. The results of the present study may also be
Table IV. Multivariate analysis of relapse-free survival.

\begin{tabular}{|c|c|c|c|}
\hline \multirow[t]{2}{*}{ Factor } & \multirow{2}{*}{$\begin{array}{c}\text { Univariate } \\
\text { analysis } \\
\text { p-Value }\end{array}$} & \multicolumn{2}{|c|}{$\begin{array}{l}\text { Multivariate } \\
\text { analysis }\end{array}$} \\
\hline & & HR $(95.0 \% \mathrm{CI})$ & $p$-Value \\
\hline \multicolumn{4}{|l|}{ Age } \\
\hline$<50 v s . \geq 50$ years & 0.004 & $0.84(0.66-1.07)$ & 0.168 \\
\hline \multicolumn{4}{|l|}{ Gender } \\
\hline Male $v s$. female & 0.263 & - & - \\
\hline \multicolumn{4}{|l|}{ CEA } \\
\hline $\begin{array}{l}<5.0 \text { vs. } \geq 5.0 \mathrm{ng} / \mathrm{ml} \\
\text { CA } 19-9\end{array}$ & $<0.001$ & $1.17(0.90-1.52)$ & 0.233 \\
\hline$<37$ vs. $\geq 37 \mathrm{ng} / \mathrm{ml}$ & $<0.001$ & $1.60(1.23-2.07)$ & 0.001 \\
\hline \multicolumn{2}{|l|}{ Tumor location } & $1.16(0.90-1.51)$ & 0.252 \\
\hline \multicolumn{4}{|l|}{ Pathology } \\
\hline Well/mod vs. poor/muc & 0.095 & - & - \\
\hline \multicolumn{4}{|l|}{ T-Stage } \\
\hline $1-2$ vs. 3-4 & $<0.001$ & $2.21(1.53-3.29)$ & $<0.001$ \\
\hline \multicolumn{4}{|l|}{ N-Stage } \\
\hline $0 v s .1$ & $<0.001$ & $1.87(1.44-2.44)$ & $<0.001$ \\
\hline \multicolumn{4}{|l|}{ M-Stage } \\
\hline 0 vs. 1 & $<0.001$ & $2.48(1.88-3.25)$ & $<0.001$ \\
\hline \multicolumn{4}{|l|}{ Lymphatic invasion } \\
\hline Absent vs. present & $<0.001$ & $1.22(0.96-1.56)$ & 0.110 \\
\hline \multicolumn{4}{|l|}{ Venous invasion } \\
\hline Absent vs. present & $<0.001$ & $1.61(1.16-2.31)$ & 0.004 \\
\hline \multicolumn{4}{|l|}{ CRC } \\
\hline Solitary vs. synchronous & 0.047 & $1.52(1.02-2.18)$ & 0.039 \\
\hline
\end{tabular}

CA19-9, Cancer antigen 19-9; CEA, carcinoembryonic antigen; CI, confidence interval; HR, hazard ratio; mod, moderately differentiated adenocarcinoma; muc, mucinous adenocarcinoma; poor, poorly differentiated adenocarcinoma; well, well-differentiated adenocarcinoma.

attributed to the differences in genetic backgrounds, including race, although we did not investigate the microsatellite instability (MSI) of whole tumors. The incidences of high MSI and CpG island methylator phenotype are reported to be lower in the East Asian population (11). The cohort in this study was mostly of Japanese descent. The frequency of high MSI in Japan is approximately 5\%, which is lower than that in America or Europe (12-14). Patients with high MSI CRC have a relatively more favorable prognosis (15). Malesci $e t$ $a l$. reported that while there were no significant differences in outcomes between synchronous and solitary MSI CRC, synchronous microsatellite stable CRC was associated with poorer outcomes than solitary CRC (16).

In the present study, there was a significantly greater proportion of MACs in the synchronous CRC group. Hu et al. reported that MACs were observed in $52.0 \%$ of patients with synchronous CRC and were especially common in patients with synchronous MSI CRC (17). Lam et al. also demonstrated that MACs were more frequently observed in patients with 
a

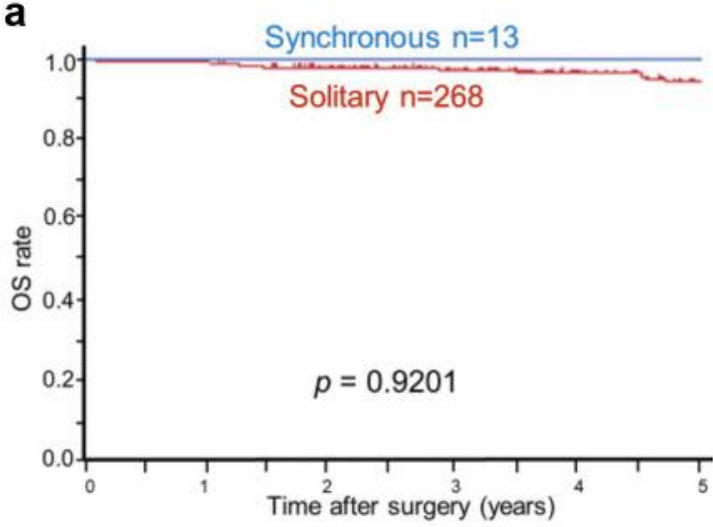

C

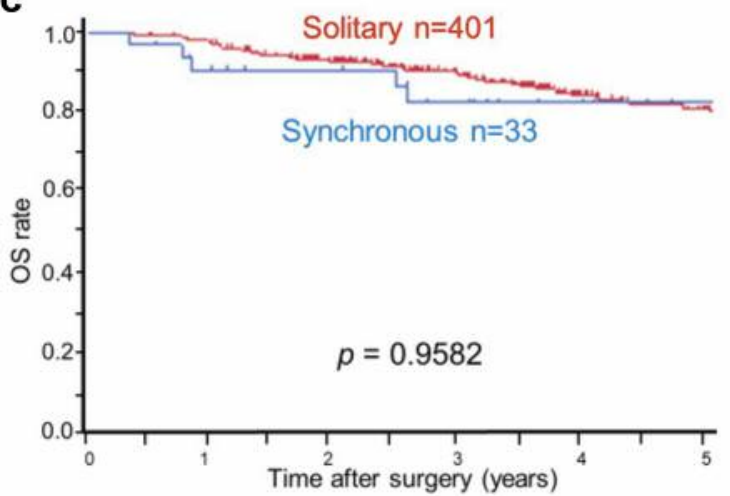

b

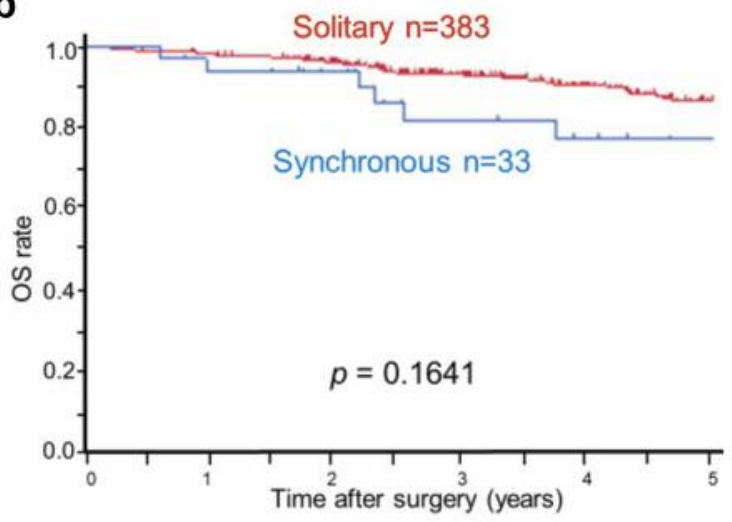

d

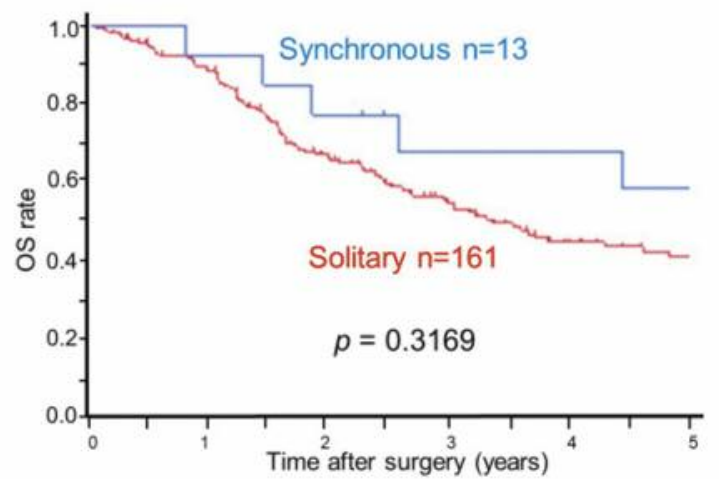

Figure 2. Kaplan-Meier curves of overall survival (OS) in patients with stage I (a), II (b), III (c), and IV (d) disease. Blue lines represent patients with synchronous colorectal cancer (CRC); red lines represent patients with solitary CRC.

synchronous CRC than in those with solitary CRC (1). There have also been reports stating that the frequency of MACs is approximately the same for both types of CRC $(4,17)$. However, as Nosho et al. (7) reported, synchronous CRC is associated with higher MSI. Considering that MACs are common in MSI (18), the belief that MACs are more common in synchronous cancer is believed to hold true. The findings of the present study also support this conclusion.

As shown in our results, the relapse rate was higher in patients with synchronous CRC than in those with solitary CRC. Therefore, it may be prudent to more proactively consider postoperative adjuvant chemotherapy for patients with synchronous CRC. When relapse occurs, it is important to analyze molecular markers at the site of relapse in order to select the most appropriate anticancer or molecularly targeted drugs. It is also important to analyze molecular markers at sites of relapse in synchronous CRC, as it is not possible to determine which tumor the metastasis has originated from. This may result in a change in the chemotherapy drug. In cases of Kristen rat sarcoma viral oncogene homolog (KRAS) wild-type and mutant tumors, it may be necessary to use a KRAS antibody to check the status of KRAS at sites of metastasis and recurrence. If tissue collection is difficult, a liquid biopsy using blood samples may be effective. In the future, it will be important to consider clinically based molecular analysis at sites of tumors or recurrence in patients with synchronous CRC.

The limitations of the present study include the fact that this was a single-center study. Therefore, the potential for population bias cannot be ruled out. The population may have been biased with respect to genetic background, which is considered particularly important for prognosis. The reason why a significant difference in OS was not observed in this study may have been because it was a single-center study with a short follow-up. Another limitation is that molecular markers, such as MSI, were not analyzed in this study. Finally, postoperative adjuvant chemotherapy was not evaluated. Therefore, its effect on prognosis remains unknown. 
a

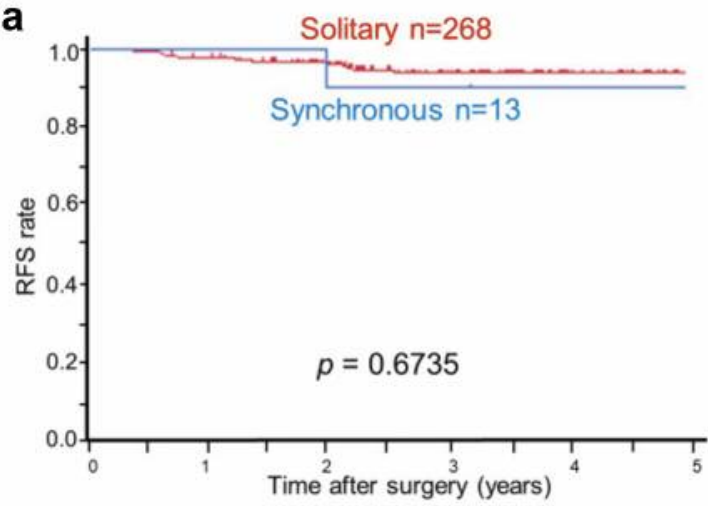

C

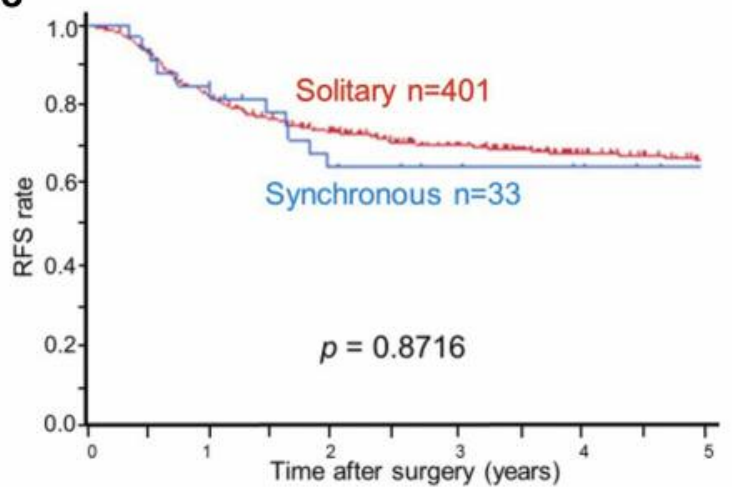

b

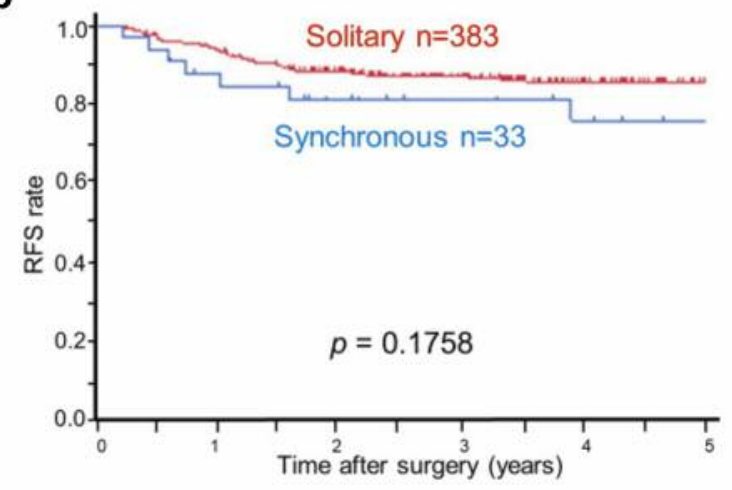

d

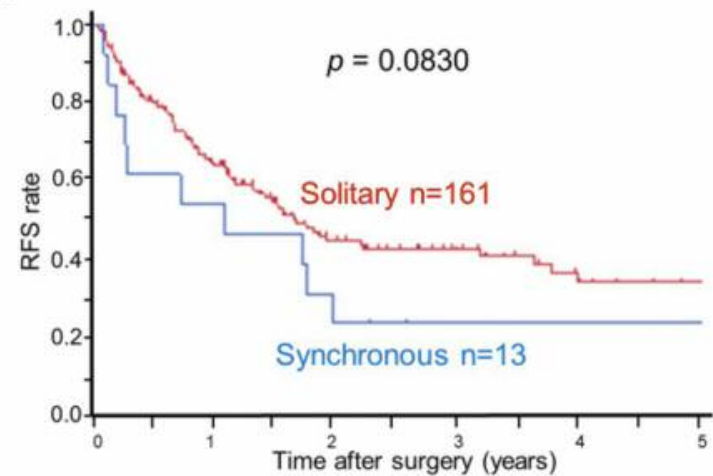

Figure 3. Kaplan-Meier curves of relapse-free survival (RFS) in patients with stage I (a), II (b), III (c), and IV (d) disease. Blue lines represent patients with synchronous colorectal cancer $(C R C)$; red lines represent patients with solitary CRC.

In conclusion, synchronous CRC is associated with a poorer 5-year RFS compared to solitary CRC. MACs are more prevalent in patients with synchronous CRC than in those with solitary CRC.

\section{Acknowledgements}

This research was supported by Grants-in-Aid for Scientific Research (C) (grant numbers: 16K07143, 16K07161, 17K10620, 17K10621, 17K10623, and 18K07194) from the Japan Society for the Promotion of Science and by the Project for Cancer Research and Therapeutic Evolution (grant number: 18cm0106502h0003) from the Japan Agency for Medical Research and Development.

\section{References}

1 Lam AK, Chan SS and Leung M: Synchronous colorectal cancer: clinical, pathological and molecular implications. World J Gastroenterol 20: 6815-6820, 2014.

2 Huang CS, Yang SH, Lin CC, Lan YT, Chang SC, Wang HS, Chen WS, Lin TC, Lin JK and Jiang JK: Synchronous and metachronous colorectal cancers: Distinct disease entities or different disease courses? Hepatogastroenterology 62: 286-290, 2015.
3 Latournerie M, Jooste V, Cottet V, Lepage C, Faivre J and Bouvier AM: Epidemiology and prognosis of synchronous colorectal cancers. Br J Surg 95: 1528-1533, 2008.

4 Mulder SA, Kranse R, Damhuis RA, de Wilt JH, Ouwendijk RJ, Kuipers EJ and van Leerdam ME: Prevalence and prognosis of synchronous colorectal cancer: A Dutch population-based study. Cancer Epidemiol 35: 442-447, 2011.

5 Bekdash B, Harris S, Broughton CI, Caffarey SM and Marks CG: Outcome after multiple colorectal tumours. Br J Surg 84: 1442-1444, 1997.

6 Oya M, Takahashi S, Okuyama T, Yamaguchi M and Ueda Y: Synchronous colorectal carcinoma: Clinico-pathological features and prognosis. Jpn J Clin Oncol 33: 38-43, 2003.

7 Nosho K, Kure S, Irahara N, Shima K, Baba Y, Spiegelman D, Meyerhardt JA, Giovannucci EL, Fuchs CS and Ogino S: A prospective cohort study shows unique epigenetic, genetic and prognostic features of synchronous colorectal cancers. Gastroenterology 137: 1609-1620, 2009.

8 Yang J, Peng JY and Chen W: Synchronous colorectal cancers: A review of clinical features, diagnosis, treatment and prognosis. Dig Surg 28: 379-385, 2011.

9 Warren S and Gates O: Multiple primary malignant tumors: Survey of the literature and statistical study. Am J Cancer 16: 1358-1414, 1932. 
10 Gospodarowicz MK, Brierley JD and Wittekind C: TNM Classification of Malignant Tumours. Chichester, UK, John Wiley \& Sons, Ltd., 2017.

11 Bae JM, Cho NY, Kim TY and Kang GH: Clinicopathologic and molecular characteristics of synchronous colorectal cancers: Heterogeneity of clinical outcome depending on microsatellite instability status of individual tumors. Dis Colon Rectum 55: 181-190, 2012.

12 Ishikubo T, Nishimura Y, Yamaguchi K, Khansuwan U, Arai Y, Kobayashi T, Ohkura Y, Hashiguchi Y, Tanaka Y and Akagi K: The clinical features of rectal cancers with high-frequency microsatellite instability (MSI-H) in Japanese males. Cancer Lett 216: 55-62, 2004

13 Kadowaki S, Kakuta M, Takahashi S, Takahashi A, Arai Y, Nishimura Y, Yatsuoka T, Ooki A, Yamaguchi K, Matsuo K, Muro $\mathrm{K}$ and Akagi $\mathrm{K}$ : Prognostic value of $K R A S$ and $B R A F$ mutations in curatively resected colorectal cancer. World $\mathrm{J}$ Gastroenterol 21: 1275-1283, 2015.

14 Kumamoto K, Ishida H, Suzuki O, Tajima Y, Chika N, Kuwabara K, Ishibashi K, Saito K, Nagata K, Eguchi H, Tamaru $\mathrm{J}$ and Iwama $\mathrm{T}$ : Lower prevalence of Lynch syndrome in colorectal cancer patients in a Japanese hospital-based population. Surg Today 46: 713-720, 2016.

15. Boland CR and Goel A: Microsatellite instability in colorectal cancer. Gastroenterology 138: 2073-2087, 2010.
16 Malesci A, Basso G, Bianchi P, Fini L, Grizzi F, Celesti G, Di Caro G, Delconte G, Dattola F, Repici A, Roncalli M, Montorsi $M$ and Laghi L: Molecular heterogeneity and prognostic implications of synchronous advanced colorectal neoplasia. Br J C ancer 110: 1228-1235, 2014.

$17 \mathrm{Hu} \mathrm{H}$, Chang DT, Nikiforova MN, Kuan SF and Pai RK: Clinicopathologic features of synchronous colorectal carcinoma: A distinct subset arising from multiple sessile serrated adenomas and associated with high levels of microsatellite instability and favorable prognosis. Am J Surg Pathol 37: 1660-1670, 2013.

18 Kazama Y, Watanabe T, Kanazawa T, Tada T, Tanaka J and Nagawa $\mathrm{H}$ : Mucinous carcinomas of the colon and rectum show higher rates of microsatellite instability and lower rates of chromosomal instability: a study matched for $\mathrm{T}$ classification and tumor location. Cancer 103: 2023-2029, 2005.

Received August 27, 2018

Revised September 10, 2018

Accepted September 12, 2018 